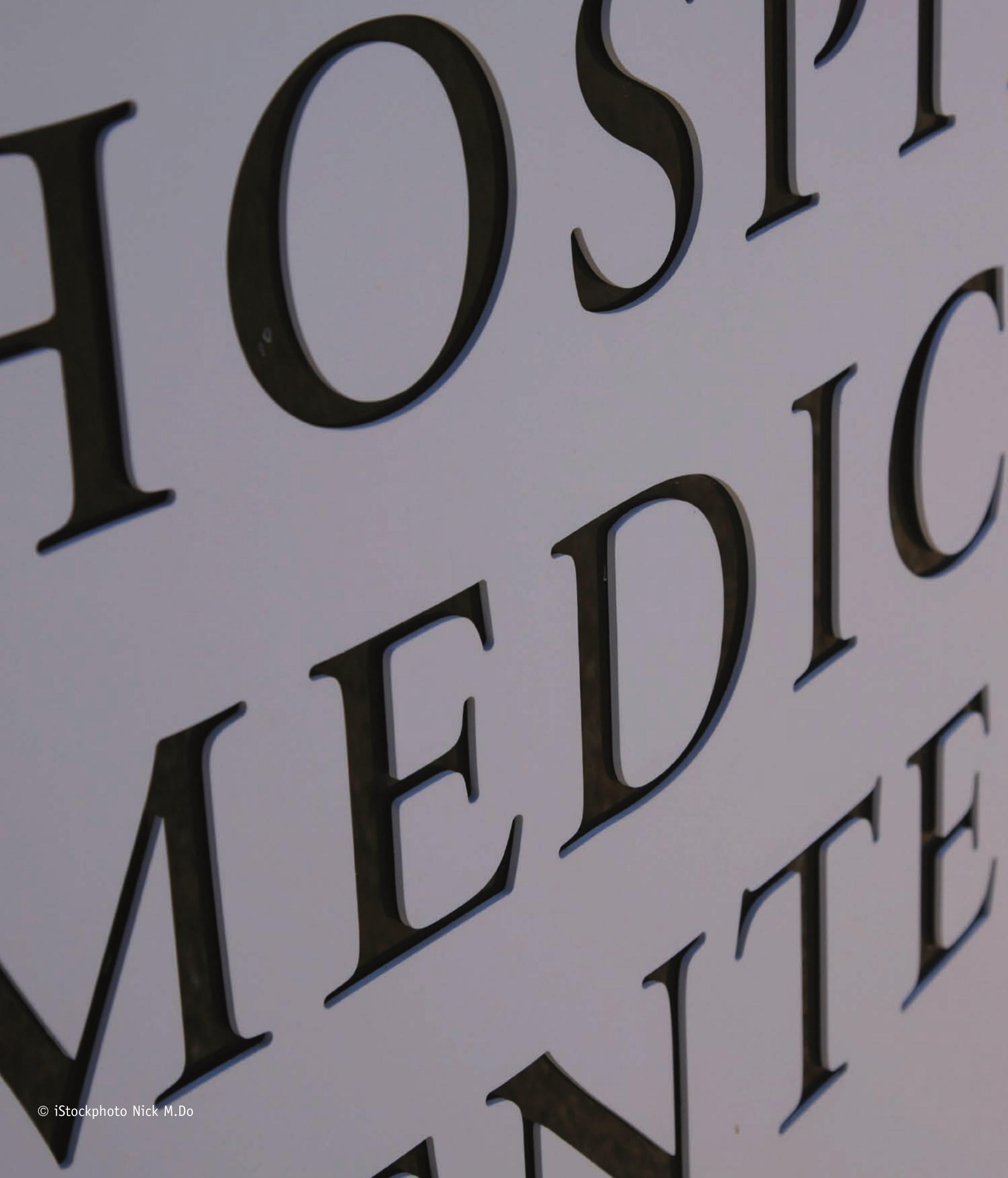




\section{Adult HERMES: criteria for accreditation of ERS European training centres in adult respiratory medicine}

\section{Introduction}

Respiratory diseases place considerable burden on society and are among the leading causes of mortality worldwide. Within the European Union, these diseases account for $17 \%$ of male and $10 \%$ of female deaths [1]. In monetary terms, the European Lung Foundation (ELF)/European Respiratory Society (ERS) estimates economic burden at approximately $€ 102$ billion or $€ 118$ per capita [2]. It is concluded that failure to diagnose, treat or manage respiratory diseases, results not only in higher treatment costs, but also impacts upon quality of life and well-being for the patient. Subspecialty training and career development of the young respiratory specialist has been identified as a fundamental aspect of delivering quality care and strengthening respiratory medicine. Moreover, as adult respiratory specialists increasingly seek opportunities abroad, the harmonisation of standards to train specialists in respiratory medicine across Europe becomes crucial.

Working towards consistent criteria for respiratory medicine, ERS, since 1990, continues to produce consensus statements and clinical practice guidelines on issues related to this field of medicine. In 2005, as part of the mission to advance the practice of the specialty, the HERMES (Harmonised Education in Respiratory Medicine for European Specialists) project was born to provide a shared framework for the training and certification of adult respiratory specialists across countries. Justification for the project grew from results of a number of surveys carried out by ERS [3] confirming the stark differences of medical educational programmes and lack of homogeneity of syllabus, curriculum and exit criteria for training of adult respiratory specialists.

Within the HERMES model, a process of establishing consensus standards for training largely follows four key phases (fig. 1) with the goal of developing collective documentation and activities. To date, three of the phases have been published and delivered by the HERMES Task Force, and are available in the international public domain for use as a basis for training and assessment.

\section{European syllabus}

The HERMES syllabus for adult respiratory medicine was published by the Task Force in 2006 [4] producing a consensus-based document outlining the core skills and competencies that a practicing specialist in the field should possess.

\section{European curriculum}

The syllabus document was further developed to create the HERMES Curriculum, published in 2008 [5], and essentially considered the educational processes required to ensure adequate teaching, learning and assessment of the listed syllabus knowledge items.

\section{European examination}

The knowledge-based HERMES Examination originates from the HERMES syllabus, covering 90 multiple-choice questions over $3 \mathrm{~h}$. Individuals have the opportunity for three different
R. Loddenkemper
T. Séverin
S. Mitchell
A. Belevskiy
A. Chuchalin
S. de Hosson
G. Di Maria
S. Hartl
I. Horvath
C. Leroyer
J-L. Noel
B. Nybo
G. Phillips
$R$. Stevenson
M. Zach
P. Palange 


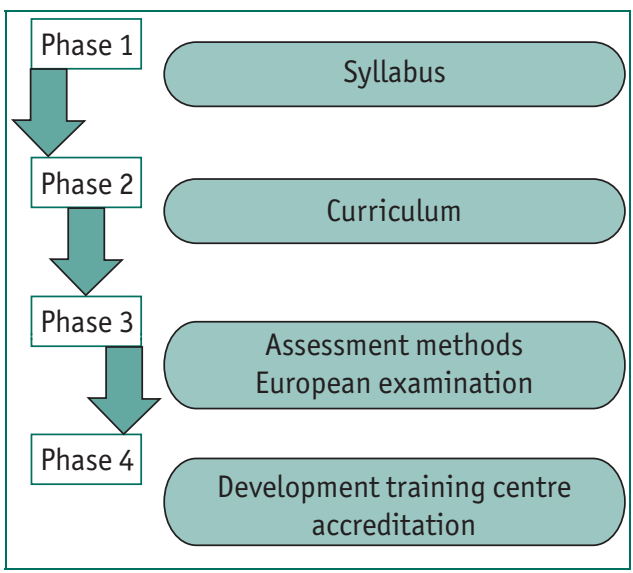

Figure 1

The four key phases of the HERMES model.

options should they wish to sit the examination: a) in-training assessment for those currently within the speciality training period; b) selfassessment open to all medical practitioners who would like to benchmark themselves and; $c$ ) European Diploma for those who are nationally accredited adult respiratory specialists.

To support the HERMES initiative, a number of educational resources have been developed in conjunction with the HERMES standards and certification documents (fig. 2). The ERS Handbook of Respiratory Medicine [6] is the most recent, yielding great success. The textbook was launched at the ERS Annual Congress Barcelona 2010 and presents an overview of each of the modules listed within the HERMES syllabus. The HERMES website [7] and the ERS Handbook website further extend the pool of learning resources offering guidelines and CMEaccredited questions, strengthening the HERMES initiative.

Today, the HERMES documents and examination are recognised as a mark of European

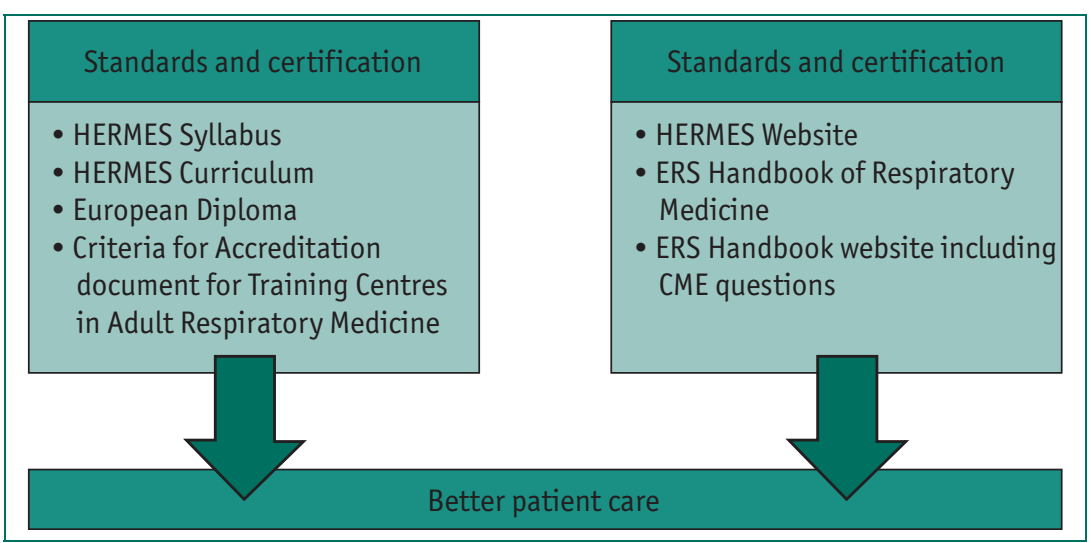

Figure 2

The HERMES initiative has been developed in conjunction with numerous educational resources. excellence across national societies. The HERMES examination was afforded legal recognition as the official part I exit examination in adult respiratory medicine for Swiss trainees. The Netherlands participated in an annual in-training assessment for Dutch respiratory medicine trainees in October 8, 2010 with the possibility of adopting the exam either as a yearly intraining examination or exit examination. Spain encourage their trainees to sit the examination offering to sponsor anyone who wishes to take part, and Austria have also endorsed the HERMES exam as legally equivalent to their official national exit examination, a raising status which is allowing the HERMES initiative value, respect and legal recognition within Europe. In the concluding phase of the adult HERMES initiative, the ERS Criteria for Accreditation document represents the final efforts of the Adult HERMES Task Force to attain the overarching goal of harmonising training and ensure continued and sustained quality improvement of training for the subspecialty of adult respiratory medicine.

\section{Historical background}

Accreditation is typically defined as a voluntary process whereby a professional association or society assesses the healthcare organisation to establish if predetermined criteria (or standards) have been met [8]. The process of accreditation is to ensure continuous assurance of healthcare for patients and implementation of recommended minimum standards. Historically, accreditation concentrated on safe and effective care within the familiar focus of the structure of the hospital and determining standards for the physical make-up and equipment for example. Since the birth of the Joint Commission in 1910, the accreditation process has evolved to include a variety of initiatives from "medication management and use" to "information management" and to include processes and outcomes in accreditation practices [9].

In 1993, the European Union of Medical Specialists (UEMS) published the Charter on Training of Medical Specialists in the European Community, directive 93/16/EEC of 5 April $1993[10,11]$, to mutually recognise basic and specialist medical qualifications across European countries in an effort to open the European job market for specialists practising their speciality. The intended purpose of this initiative has failed to echo the reality that movement across international boundaries 
continues to be difficult for practicing specialists [12].

Within the scope of the HERMES initiative, employing standards for education and training of the trainee is essential to practice high-quality adult respiratory medicine and improve mobility across countries. In order to lead HERMES towards this end goal, each phase intends to cover key criteria to standardise training and educational activities. The Task Force recognised that in order to ensure all facets of the educational continuum are covered, a published document incorporating quality measures is necessary. This document should facilitate assessment and confirm that those carrying out training do so with appropriate knowledge and authority. Consequently, the Task Force presents the document on ERS Criteria for Accreditation, representing the consensus-based standards and measurable criteria required to accredit training centre networks within Europe.

\section{Methodology}

Utilising a number of specific and individual processes, in June 2009, the Task Force began the assignment of developing the ERS Criteria for Accreditation document. Accreditation is dependent upon a robust structure for assessment and success demands a simple, easy-toobserve regime to allow for implementation. The first process challenged the Task Force to find a straightforward model which could be adapted to incorporate European consensus-based standards. A skeleton structure, utilising a number of reference documents [13-17], was presented to the Task Force in June 2009, and development of the document began.

In line with stipulations of the project, the Task Force recognised a need to include indicative numbers of procedures which the training centre has to perform yearly to ensure the trainees' adequate exposure. The growth of the ERS Criteria for Accreditation document was thus dependent upon the wider expertise of respiratory medicine practitioners including trainees, and sought feedback from those working within educational and clinical supervisory roles, as well as appealing to national delegates across Europe. The second process employed an online survey tool to reach this wider audience and collect expert opinions on the indicative number of procedures to be performed by the training centre annually to ensure trainees' adequate exposure. Although the aspirations of the Task Force to retrieve usable results were immersed in doubt, (due to inconclusive results collated in a preliminary survey of the same nature) a clear trend in responses emerged from this particular survey. In December 2010, the survey was distributed and findings from the survey were deliberated among the Task Force for each procedure and successfully employed and included within the document during the March 2010 Task Force meeting.

Between September 2009 and March 2010, the Task Force discussed and considered criteria to be included in each of the eight sections of the document (fig. 3) utilising a number of reference documents $[4,5,13-23]$. In March 2010, the remaining sections were finalised and the ERS Criteria for Accreditation document was created.

\section{Results}

With the intention of providing criteria for training institutions to follow, the ERS Criteria for Accreditation document was composed and structured in eight specific sections (fig. 4). Each of the developed sections constitute the minimum recommended criteria that training centre networks should aim to incorporate for the medical training of adult respiratory specialists. The objective of this phase sought to generate an inclusive, flexible and simple model to ensure participation and allow enough flexibility to adopt criteria at national levels. For each meeting, the Task Force concentrated on addressing each section with care and consideration, utilising specifications within the HERMES

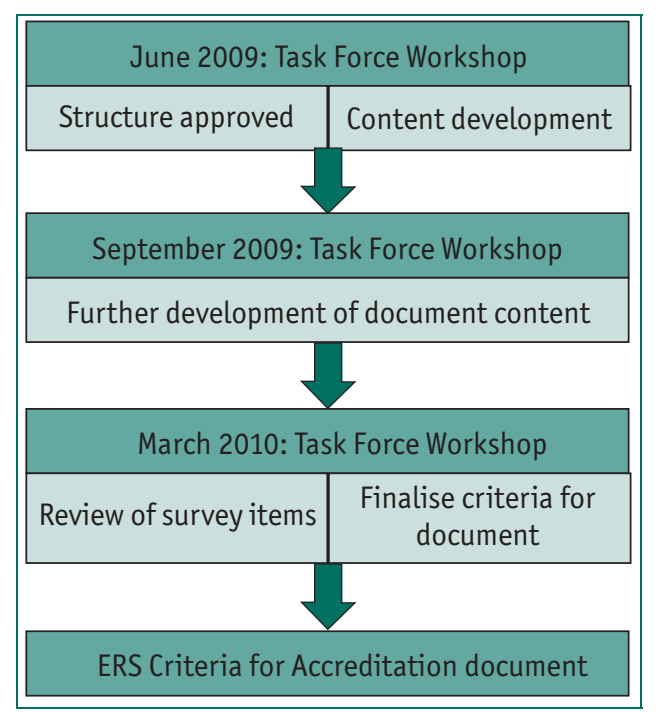

Figure 3

Timeline of the ERS Criteria for Accreditation document. 


Section 1: Training center network: Participating
sites and network structures
1. Training center network definition
Section 2: Minimum components for a full training
programme in adult respiratory medicine
1. Trainee selection
2. Duration of training
Section 3: Content of clinical experience
Section 4: Content of educational experience
1. Educational methods
2. Assessment toolbox
Section 5: Content of research/scientific
experience
Section 6: Infrastructure and support for trainees
1. Educational facilities
2. Clinical support facilities
3. Clerical support
Section 7: Organisation of training programme
1. Programme director
2. Teaching faculty
3. Other organisational issues
4. Multidisciplinary approach
Section 8: Requirements for specific facilities
1. Indicative numbers for lung function testing
2. Indicative numbers for other procedures
performed collaboratively
3ndicative numbers for procedures
(n)

Figure 4

Structure of the ERS Criteria for Accreditation document.

syllabus and curriculum. In March 2010, a comprehensive document including the guidelines and criteria for European accreditation of training centre networks was completed.

\section{Discussion}

If we consider the successful deployment of standardised processes within the sphere of medical training, the process of accreditation is most certainly one of the most challenging to implement. Success of this phase is dependent on a rigorous structure applicable to hospital training centres. The Task Force were met with a number of challenges in developing a simple, effective and appropriate document for accreditation.

\section{Challenges}

To effectively achieve success in this project, phase specific development areas were considered necessary: 1) documented minimum criteria; 2) requirements for the accreditation process; and 3) supporting documentation to determine if prerequisites are met, including questionnaires for example. The Criteria for Accreditation document marks the completion of this first step. The next issue for address is to determine a structure for the accreditation process. In fact, the accreditation process was considered during the development of the ERS Criteria for Accreditation document, as the final section of the document. Five specific criteria will need to be addressed within this section, including the accrediting body, selfreporting, the visitation programme, certification of accreditation and costs. This section was produced on the wellestablished accreditation practice of site visitation $[14,23,24]$. Within this section, the whole process of accreditation was considered utilising methods, including questionnaires, log-books and interviews. Visitation of the training centre would be granted pertaining to criteria set out within the questionnaires. It is intended that this section will be published on the ERS website [25] as soon as it is finalised.

The difficulties surrounding implementation of a voluntary process of accreditation were further researched by the Educational Activities department of ERS, whereby a benchmark analysis was conducted to assess the resources required to support such a structure. The results of the analysis only served to confirm impending complexities especially highlighting the costs required and potential exclusion of those training centres unable to afford ERS accreditation. A decision was taken by the Task Force that initiatives, including potential collaboration with national and European societies as well as the possibility of offering financial support, would be further investigated.

\section{Country perspective}

Customs surrounding the medical 'teaching hospital' and indeed the practices of medicine in more generic terms is a discipline deeply rooted in tradition, culture and boundaries created by a long-standing history of social practices. To adopt uniform standards and new expectations of educational procedures is more than just a change in routine practice; rather, it is the realisation of required changes of attitudes and behaviours within that institution [26]. The reality today resonates a current disconnect in training of adult respiratory specialists across Europe. Consequently, teaching institutions taking part in ERS accreditation will not all 
encounter the same challenges. While some educational training programmes of respiratory medicine will have little or no modifications to reach European certification, others will need to consider a framework for educational redesign.

With the great intention of the HERMES Task Force to open accreditation to all training centre networks of adult respiratory medicine, irrespective of geographical location, emphasis of certification focuses on development, education and quality assurance. Sustained quality improvement of training in adult respiratory medicine is the end goal.

\section{Conclusion}

Education is undoubtedly one of the primary mechanisms to ensure a better future for the practice of specialist medicine and, more specifically, the practice of adult respiratory medicine. At the centre of this focus, the adult HERMES initiative attempts to establish coherence between national standards and broader European aspirations of harmonisation. It is intended that training centres in adult respiratory medicine use the ERS Criteria for Accreditation document as a blueprint for best practice for structure and training, and recognise that the potential gains in terms of patient care are real and significant. Building on the success afforded to the activities and documents developed within the first three project phases, with great confidence, the Task Force moves one step closer towards their intended mission: to Harmonise Education and training in Respiratory Medicine for European Specialists!

\section{Acknowledgements}

The following experts participated as national respondents: Altraja. A (Estonia), Chovan.L (Slovakia), Costello. R (Ireland), Danila. E (Lithuania), Delaunois. L (Belgium), Gaga. M (Greece), Hansson. L (Sweden), Hesse. P (Austria), Ivanov. Y (Bulgaria), Joos. L (Switzerland), Keser. D (Bosnia-Herzegovina), Kinnula. V (Finland), Kocabas. A (Turkey), Kosnik. M (Slovenia), Kozielski. J (Poland), Krams. A (Latvia), Laursen. L (Denmark), Lorenz. J (Germany), Mihaltan. F (Romania), Petrovic. V (Serbia \& Montenegro), Rakusic. N (Croatia), Rodriguez De Castro. F (Spain), Rosin. R (Sweden), Smeenk. F (Netherlands), Sotto-Mayor De Azevedo e Castro. R (Portugal), Tamm. M (Switzerland), Tollali. T (Norway), Zatloukal. P (Czech Republic).

\section{References}

1. European Commission in Public Health. Responding to the need of respiratory system mortality comparable data, Available from: http://ec.europa.eu/health/ph_information/dissemination/diseases/respiratory_en.htm Date last accessed: July 8, 2010.

2. The Burden of Lung Disease, In: Loddenkemper R, Gibson GJ, Sibille Y, eds. European Lung White Book: The First Comprehensive Survey on Respiratory Health in Europe. Sheffield: European Respiratory Society/European Lung Foundation, 2003; pp. 2-13.

3. Loddenkemper R, Séverin T, Eiselé J-L, et al. HERMES: good reasons for harmonising education and training in respiratory medicine. Eur Respir J 2006; 28: 470-471.

4. Loddenkemper R, Haslam PL, Séverin T, et al. HERMES: a European Core Syllabus in Respiratory Medicine. Breathe 2006; 3: 59-70.

5. Loddenkemper $\mathrm{R}$, Haslam PL, Séverin $\mathrm{T}$, et al. European curriculum recommendations for training in adult respiratory medicine: 2nd report of the HERMES Task Force. Breathe 2008; 5: 80-93.

6. Palange P, Simonds A, eds. ERS Handbook: Respiratory Medicine. Sheffield: European Respiratory Society, 2010.

7. Harmonising Education in Respiratory Medicine for European Specialists. http://hermes.ersnet.org

8. Joint Commission International. Joint Commission International Accreditation Standards for Hospitals. Third Edn, Illinois: Joint Commission International, 2007.

9. World Health Organisation - Technical Discussions. Accreditation of Hospitals and Medical Education Institutions - Challenges and Future Directions, EM/RC50/Tech.Disc. 1 August 2003. www.emro.who.int/whd2006/Media/PDF/ RC50_Jor_2005.pdf Date last accessed: July 8, 2010.

10. Union Européenne des Médecins Spécialistes, European Board of Pneumology. UEMS Charter on Training of Medical Specialists in the EU: requirements for the speciality of pneumology 93/16/EEC of 5 April 1993

11. UEMS, European Board of Pneumology, Chapter 6, Charter on Training of Medical Specialists in the EU $1995 \mathrm{http}: / /$ admin.uems.net/uploadedfiles/293.pdf Date last accessed July 9, 2010.

12. Loddenkemper R, Séverin T, Haslam PL. European curriculum recommendations for training in adult respiratory medicine: crossing boundaries with HERMES. Eur Respir J 2008; 32: 538-540.

13. AGCME, Program Requirements for Fellowship Education in the Subspecialties of Internal Medicine Approved ACGME 28 September 2004, Effective 1 July 05, Editorial Revision 25 April 2005. Available from: http://www.acgme.org/ acWebsite/downloads/RRC_progReq/146pr707_ims.pdf Date last accessed: June 22009.

14. UEMS management council, Charter on Visitation of Training Centers, (meeting in Killarney, Ireland 1997). Available from http://admin.uems.net/uploadedfiles/179.pdf Date last accessed: October 5, 2010. 
15. Lusznat R, King J, du Boulay C. The Wessex Deanery Strategy for Professional Support, January 2009, Available from www.nesc.nhs.uk/Docs/Wess_Prof_Support_Strategy_updated_20090514.doc Date last accessed: November 2010.

16. White W, Schwartz J, the Philadelphia Clinical Supervision Workgroup. The Role of Clinical Supervision in Recoveryoriented Systems of Behavioral Healthcare, Philadelphia: Department of Behavioral Health and Mental Retardation Services, 2007.

17. UEMS European Board of Paediatrics, Visitation for Accreditation, Data Collection Forms. Available from: www. eapaediatrics.eu/index.php?option $=$ com_content\&view $=$ article\&id $=67 \% 3$ Avisitation-andexamination\&catid=19\&Itemid $=3$ Date last accessed: August 2, 2010.

18. Residency Review Committee, Special Requirements for Residents Training in Ophthalmology as recommended by the Residency Review Committee of the European Board of Ophthalmology, 2002, Available from http://ebo-online. org/newsite/committee/residency_rev/requirements.asp Date last accessed: July 9, 2010.

19. The Care Quality Commission Website, Patient Surveys. Available from: www.cqc.org.uk/publications. $\mathrm{cfm} ?$ widCall1 $=$ customDocManager.search_do_2\&tcl_id $=1 \&$ search_string $=\&$ top_parent $=5044$ Date last accessed: June 2, 2009.

20. UEMS Union Européenne des Médecins Spécialistes, European Board of Anaesthesiology ESA. Policy and Procedures: Hospital Visiting and Accreditation Programme HVAP. 1989.

21. Sweeney J, Brooks AM, Leahy A. Development of Irish National Patient Perception of Quality of Care Survey. Int J Qual Health Care, 2003; 15(2): 163-168.

22. Instructional Methods and the Clinical Learning Setting: An educational guide for the implementation of the Paediatric HERMES curriculum. J0 Busari, et al. in press. 2010 This document is a work in progress and should not be referenced unless and until it is approved and published. Until such time as this Editor's Note is removed, the inclusion of the above document is for informational purposes only.

23. Zach M, Milla P, European Training Centre Visitation Program for Tertiary Care Pediatric Specialties. 2003 1-12, Available from: $w w w$.eapaediatrics.eu/index.php?option $=$ com_content\&view $=$ article\&id $=67$ :visitation-andexamination\&catid=12:docs\&Itemid=80 Date last accessed: 0ctober 5, 2010.

24. Zach MS, et al. Paediatric respiratory training in Europe: syllabus and centres. Eur Respir J 2002; 20: 1587-1593.

25. European Respiratory Society. www.ersnet.org/

26. World Health Organization - World Federation for Medical Education, Accreditation of medical education institutions, report of technical meeting, Schaeffergarden, Copenhagen, Denmark, 4-6 October, 2005. Available from: www.who.int/hrh/documents/WFME_report.pdf Date last accessed: July 10, 2010. 


\section{CRITERIA FOR ACCREDITATION OF ERS EUROPEAN TRAINING CENTRES IN ADULT RESPIRATORY MEDICINE}
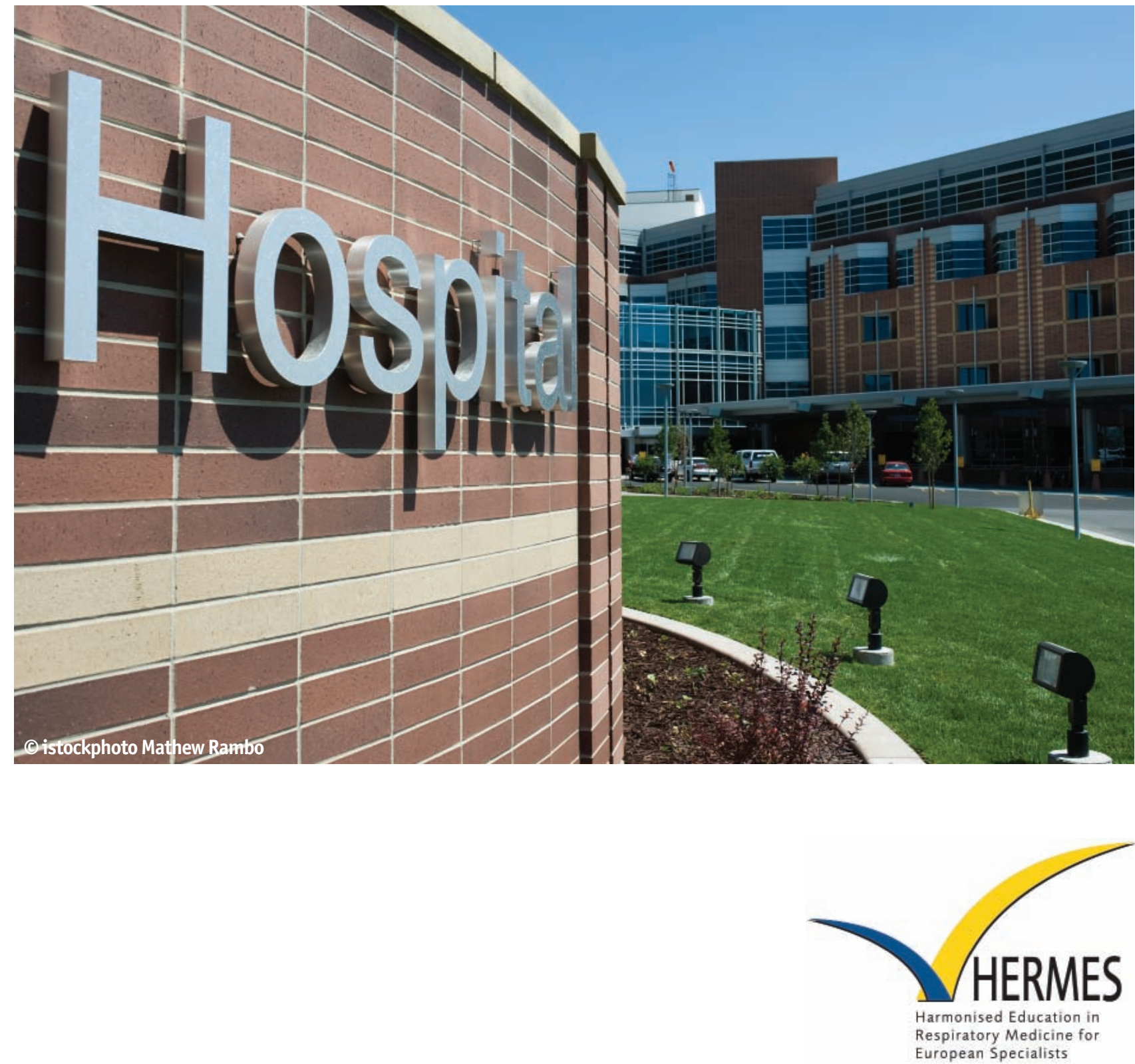


\section{Contents}

$\begin{array}{lr}\text { Preamble } & 179\end{array}$

$\begin{array}{ll}\text { Introduction } & 179\end{array}$

Section 1: Training centre network: participating sites and network structure $\quad 180$

1. Training centre network definition: 180

Section 2: Minimum components for a full training programme in adult respiratory medicine $\quad 180$

1. Trainee selection 180

2. Duration of training 180

$\begin{array}{ll}\text { Section 3: Content of clinical experience } & 180\end{array}$

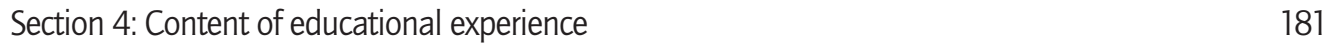

$\begin{array}{ll}\text { 1. Educational methods } & 181\end{array}$

2. Assessment toolbox 182

Section 5: Content of Research/scientific experience 183

Section 6: Infrastructure and support for trainees 183

1. Educational facilities 183

2. Clinical support facilities 183

3. Clerical support 183

$\begin{array}{ll}\text { Section 7: Organisation of training programme } & 184\end{array}$

1. Programme director 184

2. Teaching faculty 184

3. Other organisational issues 185

4. Multidisciplinary approach 185

$\begin{array}{ll}\text { Section 8: Requirements for specific facilities } & 186\end{array}$

1. Indicative numbers for lung function testing 187

2. Indicative numbers for other procedures 187

3. Indicative numbers for procedures performed collaboratively 188 


\section{Preamble}

The accreditation phase of the Adult HERMES (Harmonised Education in Respiratory Medicine for European Specialists) project was launched to ensure that training centres in adult respiratory medicine across Europe and beyond have the opportunity to be awarded a certification of excellence for their educational programmes in respiratory medicine training. To successfully implement an accreditation process, specific development areas were considered necessary:

1. Documented minimum criteria

2. Requirements for the accreditation process

3. Supporting documentation to determine if prerequisites are met

The ERS Criteria for Accreditation of ERS European Training Centres in adult respiratory medicine document marks this first step of the project phase. Titles and structures outlined within the document as well as indicative numbers presented can be country specific and may vary. The document should be used as a guideline for best practice and is intended to provide training centres with descriptions of functions and roles important for achieving high-quality training of adult respiratory specialists.

\section{Introduction}

This document provides a series of recommendations which training centres should match in order to be recognised as European training centres by the ERS in the frame of the HERMES initiative. Minimum conditions to ensure appropriate clinical and educational experience for all trainees enrolled in the training programme and procedures to be followed to become formally accredited as an ERS European training centre are also described.

Benefits for the training centre in adhering with recommendations:
a. Proof of excellence
b. Higher visibility
c. Quality label/ reputation
d. Increasing attractiveness for trainees
e. Incentive for sufficient dimension of staff, room and equipment including the full spectrum of diagnostic and therapeutic techniques, according to the curriculum
f. Incentive for better funding and better grants for research 


\section{Section 1: Training centre network: participating sites and network structure}

1. Training centre network definition:

a. A training centre network can be composed of either one single, central, participating site or of a primary training site which is formally linked with other secondary training sites.

b. The primary training site is defined as the site which provides the required training resources, where the programme director's major activity is located, where trainees spend the majority of their clinical training time.

c. Secondary sites are defined as the sites which provide specific training resources, which may provide specific training in some specialised areas, and where trainees spend a minor part of their clinical training time.

d. When a training centre network is composed of more than one site, formal letters of agreement defining roles and responsibilities must exist between the primary site and each secondary site.

\section{Section 2: Minimum components for a full training programme in adult respiratory medicine}

\section{Trainee selection}

a. Trainee selection should be performed as defined in section 3.5 of the curriculum [1], and in accordance with national rules and customs and, for EU countries, in accordance with EU regulations.

b. The training centre should provide at least one full-time equivalent position (FTE) of trainee for each year of the training duration, averaged out over the whole training duration (i.e. 3 FTEs for a 3-year training programme).

\section{Duration of training}

a. Duration of training

i. Duration of training should comply with the conditions set in section 3.5 of the curriculum, and in accordance with national rules and customs and, for EU countries, in accordance with EU regulations.

b. Calendar months

i. Prior to entering specialty training, a common trunk in General Internal Medicine (GIM) of a usual 3 years is recommended.

ii. Following GIM training, at least 3 years of subspecialty training in respiratory medicine are necessary.

c. Optional training (elective training)

i. The training centre mustset up a mechanism to allow trainees to go out of the programme, where appropriate, and do elective training or research over an agreed period of time. This elective training must take place in addition to the recommended 3 years of specialty training.

\section{Section 3: Content of clinical experience}

The training centre must ensure that the training programme provides trainees with a balanced mix of clinical experience and educational opportunities.

a. Outpatient services

i. An indicative 150 new outpatients and 400 follow-up patients per year and per trainee, averaged over the whole training period are recommended.

b. Provision for special outpatient services:

The training centre network must be able to provide a wide range of outpatient senvices, for example: 
i. COPD and asthma

ii Lung cancer

iii. Interstitial lung disease

iv. Cystic fibrosis

v. Oxygen treatment and home ventilation

vi. Pulmonary hypertension

vii. Respiratory infections including tuberculosis

viii. Respiratory disorders during sleep

ix. Pulmonary vascular diseases

c. Inpatient services

i. The training centre must be able to provide a sufficient number of patients to cover the spectrum of respiratory diseases defined in the syllabus [2].

ii. An indicative 300 inpatients peryear per trainee, averaged over the whole training period are recommended.

d. Logbook/Portfolio

i. It is recommended that trainees keep a logbook/portfolio which should be regularly signed by the educational and/or clinical supervisor. Data collected in the logbook must be anonymous.

e. Referrals

i. The training centre must ensure trainer availability for discussion with trainees for each referral in order to ensure education and clinical governance.

ii. Consultations from other clinical services must be accessible in a timely manner.

\section{Section 4: Content of educational experience}

a. Educational goals:

i. The training centre must be of a sufficiently high standard to allow trainees to attain the educational values as described in the curriculum.

1. Trainees develop clinical expertise through both clinical practice and a thorough knowledge of the theory behind that practice.

2. This requires good teaching and supervision, which in turn means educator development.

3. Sound clinical practice is more than knowing a lot or being able to perform certain technical procedures, however expertly. It requires the development of professional judgement so that knowledge is utilised, and technical skills performed, appropriately.

4. Trainees need to develop a reflective approach to their practice and self-motivation in the learning process.

b. Competencies

5. The promotion of good communication with colleagues and patients.

i. The programme should be able to deliver the Knowledge, Skills, Attitudes and Behaviour described in the syllabus and curriculum.

c. Educational methods

i. With reference to the HERMES Curriculum, teaching in the clinical setting requires the establishment of a learning partnership between the educator and the trainee comparable with the traditional approach of what has been called "apprenticeship". Key considerations for the educator would be:

1. Ensuring that trainees actively observe others in clinical settings in order to see, analyse and interpret all that occurs

2. Helping trainees to engage in clinical practice at a level appropriate to their experience and needs

3. Ensuring an ongoing dialogue, both within and outside the clinical setting, between educator and trainee

4. Encouraging problem solving by the trainee in a range of different clinical settings. 
ii. The full range of modern educational methods should be used. A separate educational guide (currently in press) discusses the format and use of the following recommended methods [3].

\begin{tabular}{|l|}
\hline Educational methods \\
\hline Bedside/ward teaching \\
\hline Casebased discussion \\
\hline Direct observation of practical skills (DOPS) \\
\hline E-Learning \\
\hline Feedback on letters: assessment instrument for letters \\
\hline Grand rounds/Departmental meetings/Teaching seminars \\
\hline Morning rounds \\
\hline Operating theatre environments \\
\hline Outpatient clinics \\
\hline Peer-based learning \\
\hline Self-directed learning \\
\hline
\end{tabular}

d. Assessment methods

i. These serve a public function of accrediting a doctor's practice and its results can be used in three important ways according to the HERMES Curriculum rationale:

1. For monitoring progress in learning (also known as formative assessment)

2. For accreditation (summative assessment)

3. For selection (e.g. into a training programme, to determine progression through a training programme, and for posts following completion of a training programme).

i. The full range of modern assessment methods should be used. A separate educational guide (currently in press) discusses the format and use of the following recommended methods [3]:

\begin{tabular}{|l|}
\hline Assessment toolbox \\
\hline Audit \\
\hline Case based discussion \\
\hline Direct observation of practical skills (DOPS) \\
\hline Feedback on letters: assessment instrument for letters \\
\hline Mini-Clinical Evaluation exercise (MiniCEX) \\
\hline Multi source feedback \\
\hline Objective structured clinical examination (OSCE) \\
\hline Oral examination \\
\hline Other options for example simulation and standardised patients \\
\hline
\end{tabular}

ii. The training centre should ask its trainees to keep a logbook/portfolio, which is to be signed off by the.educational and/or clinical supervisors at regular intervals. Data collected in the logbook should be anonymised.

iii. The training centre should strongly encourage its trainees to sit the HERMES Examination after completion of training and certification as a specialist. During the process of training centre re-accreditation, this will be looked at as proof of excellence of the training programme.

iv. It is recommended that the trainee undergoes an annual review of her/his progress 
with educational and clinical supervisor as well as the programme director. This annual review might be complemented by the trainee taking the ERS annual in-training assessment.

e. Level of supervision

i. The training centre must ensure that, over the course of their training period, trainees assume increasing clinical responsibility, appropriate to their overall level of competence.

ii. The training centre must be of a sufficiently high standard to allow trainees to attain the levels of supervision/independence set forth in the syllabus.

1. Level 1: Awareness sufficient to recognise and know when to refer.

2. Level 2: Knowledge sufficient to manage with supervision (or refer).

3. Level 3: Advanced knowledge sufficient for independent specialist practice.

\section{Section 5: Content of Research / scientific experience}

a. The training centre should provide a list of its 15 best publications in the last 5 years.

b. The training centre must provide opportunities for trainees to plan, conduct, evaluate and publish research (e.g. each trainee should have presented at least one oral poster in an international congress by the end of training).

\section{Section 6: Infrastructure and support for trainees}

The training centre must ensure the availability of adequate resources for trainee education:

\section{Educational facilities}

a. Space and equipment

i. There must be adequate space and equipment to cope with the requirements of the educational programme, including meeting rooms, classrooms, examination rooms, computers with internet access, visual and other educational aids, and work/study space. A minimum of one desk per trainee and one computer per 2 trainees is recommended.

ii. The training centre must provide adequate and timely medical information access to specialty-specific and other appropriate print, electronic and web-based reference materials.

\section{Clinical support facilities}

a. The training centre must ensure the availability of adequate resources to support trainees' clinical experience:

i. Medical records must be delivered as occasion demands, including imaging, laboratory and pathological reports for both inpatient and ambulatory care patient population.

ii. Images from chest radiograph, CT scans, nuclear scans, MRI etc. which are of sufficient quality must be readily available to act as occasion demands.

iii. When trainees are assigned night duty or on call, they must be provided with facilities (rooms, catering etc.) that are convenient and that allow for sufficient privacy and safety.

\section{Clerical support}

a. The training centre must ensure the availability of adequate secretarial and administrative support to meet the needs and demands as judged by the trainee, teaching faculty and programme director. 


\section{Section 7: Organisation of training programme}

This section describes functions and roles in the organisation of a training programme important for achieving high quality training. Exact structure and titles can vary from country to country. Positions can carry other names. Furthermore, numerous responsibilities can be attributed to a single position depending on the size and structure of the local programme.

Each programme must be supervised by a single programme director who has the authority and accountability for the operation of the entire programme. The programme must ensure adequate numbers of both educational and clinical supervisors.

\section{Programme director}

a. Qualifications must include:

i. Certified specialist recognised by relevant national authority

ii. Certified as a training specialist

iii. In addition, it is recommended that the programme director has the HERMES European Diploma

iv. Should have a scientific background, have produced original research and have peerreviewed research publications

b. Administrative responsibilities include the following:

i. Oversee and ensure the efficient management and quality of the training programme

ii. Supervise and guarantee quality of didactic and clinical education at all certified European training centre networks

iii. Approve the educational supervisor at each participating site of the training centre network

iv. Ensure the quality of educational and clinical supervisors

v. Coordinate the monitoring of trainee supervision

vi. Make provision for regular trainee formative assessments at least 3 times a year

vii. Make provision for mechanisms for trainee grievances and due process

viii. Implement policies and procedures (may refer to a separate list of policies and procedures)

\section{Teaching faculty}

a. Educational Supenisor

i. Qualifications must include:

1. Certified and practising specialist

2. Strong interest and commitment to education

3. commitment to keeping up to date

4. scientific background, author of original research and peer-reviewed research publications

5. In addition, it is recommended that the educational supenvisor has the HERMES European Diploma

ii. Responsibilities include the following:

1. Oversee the progress of the trainee throughout the entire training programme

2. Conduct formal appraisals with the trainee at least every 3 months (every 3 months)

3. Comment on the educational progress of the trainee in the trainee's portfolio

4. Provide feedback on assessments and general progress of the trainee

5. Review of trainee appraisals and overall progress, and for those trainees experiencing difficulty, liaise with colleagues including the clinical supervisor to address concerns and provide additional professional support to the trainee where necessary

6. Oversee the personal and professional development of the trainee 
b. Clinical Supervisor

i. Qualifications of the clinical supervisor must include:

1. Certified and practicing specialist

2. Commitment to keeping up to date

3. Scientific background, author of original research and peer-reviewed research publications

4. In addition, it is recommended that the clinical supenvisor has the HERMES European Diploma

ii. Clinical supervisor responsibilities include the following:

1. Responsible for the continuous observation of trainee's assigned clinical work

2. Ensure assigned trainees abide with best practice in safety and clinical standards of care

3. Delegate appropriate levels of responsibility and ensure adequate supervision and support is available

4. Identify any concerns or problem areas relating to the trainee and if necessary follow up with educational supervisor

5. Monitor and record progress and solicit feedback on a regular basis to ensure practice improvement and ongoing professional development

6. Provide progress reports as requested or scheduled by the educational supenisor or programme director

c. NB: Depending on the size and structure of the training programme, educational supervisor and clinical supervisor's roles can be shouldered by one and the same person.

\section{Other organisational issues}

a. Minimum numbers of training personnel

i. The training centre must provide at least 2 full time equivalents (FTE) of certified specialists directly in charge of training.

b. Minimum number of trainees

i. The training centre should provide at least one FTE position of trainee for each year of the training duration, averaged out over the whole training duration (i.e. 3 FTEs for a 3-year training programme).

c. Duty hours and personal responsibility

i. Duty hours should conform to the local regulations of the host country.

ii. Trainees should be made aware of their responsibilities with regards to continuity of care of patients.

d. Other educational opportunities

i. The training centre must provide other educational activities such as rounds (colloquia), conferences, journal club, death reviews and autopsies, and multidisciplinary meetings.

ii. Trainees must be given opportunity to take part in teaching activities.

\section{Multidisciplinary approach}

a. The training centre must ensure smooth collaboration with other units, such as:

i. All disciplines of internal medicine

ii. Anaesthesiology

iii. Biochemistry

iv. Immunology

v. Lung transplantation

vi. Microbiology

vii. Neurology

viii. Occupational medicine

ix. Oncology

$\mathrm{x}$. Ophthalmology

xi. Otorhinolaryngology

xii. Paediatrics

xiii. Palliative care 


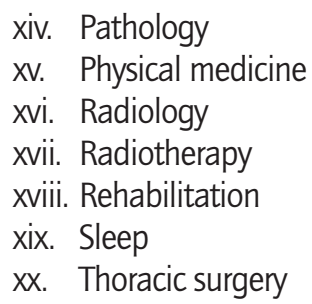

b. The training centre must ensure smooth collaboration with other professionals, such as:

i. Nurse specialists

ii. Physiotherapists

iii. Respiratory technicians

c. The training centre must ensure smooth collaboration with other care units such as:

i. Primary care

ii. Home care/early discharge (curriculum module 24)

iii. Psycho-social care (curriculum module 32)

\section{Section 8: Requirements for specific facilities}

The training centre must provide all facilities necessary to ensure that trainees experience adequate clinical experience and firsthand exposure to a wide range of techniques and procedures, as listed below. Please refer to the HERMES syllabus [2] and HERMES curriculum [1].

\begin{tabular}{|l|l|l|}
\hline Techniques and Procedures & Syllabus Item & Curriculum Module \\
\hline Imaging techniques & D.2, D.3 & 26 \\
\hline Pulmonary function testing & D.1 (including sleep studies) & 27 \\
\hline Endoscopy and interventional bronchoscopy & D.2, E.1 & 28,29 \\
\hline $\begin{array}{l}\text { Therapeutic interventions such as oxygen sup- } \\
\text { plementation, non invasive ventilation, and } \\
\text { long-term care }\end{array}$ & E.1.5, E.1.6 & 24 \\
\hline $\begin{array}{l}\text { Intensive care and high-dependency care (inter- } \\
\text { mediate care including weaning) }\end{array}$ & G.1, G.2 & 22 \\
\hline Sleep-related disorders & B.19 & 18 \\
\hline Palliative care & E.1.13 & 25 \\
\hline Tobacco dependence treatment service & E.1.19 & 21 \\
\hline
\end{tabular}

a. Indicative numbers

i. Practical experience and firsthand exposure are crucial in the learning of techniques. Per se, the number of procedures performed by a trainee is not a sufficient measure of a trainee's competence. The indicative numbers of procedures which the training centre had to perform yearly have a role in ensuring the trainees' adequate exposure. $\mathrm{A}$ trainee's experience should be recorded in the trainee's portfolio.

ii. The figures below relate to training in general adult respiratory medicine and are not relevant to those sub-specialising in one specific area of respiratory medicine, in which case they will certainly require greater numbers and higher levels of competence.

iii. It is also recognised that in some countries the stated numbers may be difficult to achieve for some techniques due to the organisation of care and the availability of facilities. However, trainee rotation through reference training centres and training centre networks offers an opportunity for most trainees in Europe to achieve these aims.

iv. Finally, simulation training is playing an increasingly important role in technical skills training and can likely reduce the numbers of actual procedures to which a trainee must have direct exposure to achieve competence. 
v. The tables below shows consensus-based indicative numbers for each procedure listed in the syllabus. Indicative numbers should be the minimum number of procedures each trainee should be directly exposed to over the entire duration of training.

vi. In addition to the indicative numbers given, it must be noted that qualified specialists must also keep the opportunity to perform procedures themselves frequently enough to remain fully skilled and competent.

\section{Indicative numbers for lung function testing}

\begin{tabular}{|l|l|l|}
\hline Syllabus item & Procedure & Indicative number \\
\hline D.1.1 & $\begin{array}{l}\text { Static and dynamic lung volumes/interpretation } \\
\text { and performance }\end{array}$ & $>100$ \\
\hline D.1.2 & Body plethysmography interpretation & $>100$ \\
\hline D.1.3 & Gas transfer interpretation & $>100$ \\
\hline D.1.4 & $\begin{array}{l}\text { Blood gas assessment and oximetry interpretation } \\
\text { and performance }\end{array}$ & $>100$ \\
\hline D.1.5 & $\begin{array}{l}\text { Bronchial provocation testing-interpretation and } \\
\text { performance }\end{array}$ & 50 \\
\hline D.1.6 & $\begin{array}{l}\text { Exercise testing including walking tests and } \\
\text { spiroergometry (cardio-pulmonary exercise testing) }\end{array}$ & $>100$ \\
\hline D.1.13 & Sleep studies interpretation and performance & 50 \\
\hline
\end{tabular}

\section{Indicative numbers for other procedures}

\begin{tabular}{|l|l|l|}
\hline Syllabus item & Procedure & Indicative number \\
\hline D.2.5 & Tuberculin skin testing & 25 \\
\hline D.2.6 & Allergy skin testing & 50 \\
\hline D.2.7 & Pleural ultrasound imaging & $>100$ \\
\hline D.2.8 & Thoracentesis & 100 \\
D.2.9 & Closed pleural needle biopsy & \\
D.2.19 & Percutaneous needle biopsy & \\
D.2.20 & Fine needle biopsy & 10 \\
\hline D.2.10 & Pleuroscopy (medical thoracoscopy) & 100 \\
\hline D.2.11 & Flexible bronchoscopy & 50 \\
\hline D.2.12 & Transbronchial lung biopsy & \\
D.2.13 & Transbronchial needle aspiration & \\
D.2.14 & Endobronchial ultrasound & \\
D.2.15 & Broncho-alveolar lavage & 50 \\
\hline D.2.17 & Rigid bronchoscopy & \\
D.2.18 & Other interventional bronchoscopic techniques & \\
& including fluorescence bronchoscopy, brachy- \\
therapy, endobronchial radiotherapy, afterload- & \\
& $\begin{array}{l}\text { ing laser and electrocoagulation cryotherapy, } \\
\text { photodynamic therapy, airway stents }\end{array}$ & \\
\hline & Pleurodesis and pleural drain insertion & 100 \\
\hline E.1.11 & & \\
\hline
\end{tabular}




\section{Indicative numbers for procedures performed collaboratively}

\begin{tabular}{|l|l|l|}
\hline Syllabus item & Procedure & Indicative number \\
\hline D.3.1 & Thoracic imaging (X-Ray, CT, MRI) & $>100$ \\
\hline D.3.2 & $\begin{array}{l}\text { Nuclear medicine techniques (pulmonary and bone scan, } \\
\text { PET) }\end{array}$ & 100 \\
\hline
\end{tabular}

vii. To calculate the minimum number of procedures per year, each training centre should then apply the following formula: multiply the indicative number by the number of trainees enrolled in their training programme, and then divide by the number of years of training to obtain a number of procedures per year:

1. Formula:

(Min No of Procedures $\times$ No of trainees) $\div$ No yrs of training

2. e.g. static and dynamic lung volumes/interpretation and performance: $>100$

3. Enrolled trainees: 6 ( 2 per year)

4. Years of training: 3

5. $(100 \times 6) \div 3=200$ Static and dynamic lung volumes/interpretation and performance per year for the whole training centre.

\section{References}

1. Loddenkemper R, Haslam PL, Séverin T, et al. European curriculum recommendations for training in adult respiratory medicine: 2 nd report of the HERMES Task Force, Breathe 2008; 5: 80-93.

2. Loddenkemper R, P.L. Haslam, Séverin T, et al. HERMES: a European Core Syllabus in Respiratory Medicine Breathe, 2006; 3: 59-70.

3. Instructional Methods and the Clinical Learning Setting: An educational guide for the implementation of the Paediatric HERMES curriculum. J0 Busari, et al. Not yet in press. 2010 This document is a work in progress and should not be referenced unless and until it is approved and published. Until such time as this Editor's Note is removed, the inclusion of the above document is for informational purposes only. 